\title{
Does self-efficacy influence the application of evidence-based practice: A survey and structural equation model
}

\author{
Kathleen Abrahamson ${ }^{1}$, Priscilla Arling ${ }^{2}$, Jenna Gillette ${ }^{1}$ \\ 1. Department of Public Health, Western Kentucky University, United States. 2. Butler University, United States.
}

Correspondence: Kathleen Abrahamson. Address: Department of Public Health, Western Kentucky University, Bowling Green, KY 42101, USA. Email: kathleen.abrahamson@wku.edu.

Received: J une 20, 2012

DOI : 10.5430/jnep.v3n5p1
Accepted: July 5, 2012

URL: http://dx.doi.org/10.5430/jnep.v3n5p1

\section{Abstract}

Background: Implementation of Evidence-Based Practice (EBP) is complex and consequently, even within organizations that have made efforts to promote EBP use, EBP is often underutilized by individual clinicians.

Purpose: The aim of our study was to better understand the relationship between self-efficacy and EBP implementation in clinical environments that have undergone efforts to increase EBP utilization. We suggest that EBP is a set of behaviors that result from individuals acquiring, applying, and sharing new knowledge with others in the organization. We hypothesize, based upon a social cognitive theoretical approach, that these behaviors are influenced by clinician perception of self-efficacy.

Methods: We analyzed data provided by a 2011 survey of clinicians working within a national sample of hospitals that were actively participating in the Clinical Practice Model Resource Center (CPMRC), a collaborative consortium of health care organizations working to guide the implementation of EBP into the work worlds of clinicians. Structural equation modeling was used to examine the relationships between the acquisition, application, and sharing of evidence, and self-efficacy.

Results: Self-efficacy increased the acquisition of evidence and application of evidence. Self-efficacy did not exert a significant influence on sharing evidence. Acquisition of evidence increased both application of evidence and sharing of evidence. Application of evidence then increased sharing of evidence among sampled clinicians.

Conclusions: Efforts to promote self-efficacy in clinicians are powerful in that they directly promote the acquisition and application of evidence, and indirectly encourage communication between clinicians in an effort to justify and reinforce new knowledge. Efforts to boost self-efficacy would benefit from a focus on helping clinicians become more comfortable with actions related to acquiring evidence and generating new knowledge.

\section{Key words}

Self-efficacy, Evidence based practice, Implementation 


\section{Introduction}

The principles of EBP are designed to decrease variability between clinicians, improve consistency of practice, provide scientific rationale for clinical decisions, and ultimately improve clinical quality ${ }^{[1,2]}$. When properly implemented, application of EBP is effective in improving patient outcomes ${ }^{[3]}$. Implementation of EBP into clinical environments is complex and consequently the principles of EBP are frequently under-utilized ${ }^{[2,4-6]}$. Much of the current literature on EBP focuses on barriers encountered during initial implementation into a clinical environment. To date there has been relatively little research on maintaining or increasing EBP use after its initial implementation.

Even in environments where evidence-based care is integrated into the organizational culture and promoted amongst staff, EBP is often not consistently integrated into the work routines of individual clinicians. Some studies have suggested that a key factor in successful implementation of EBP is a clinician's self-efficacy, defined as the belief in his or her own ability to implement evidence-based practice ${ }^{[7,8]}$. The relationship between self-efficacy and practice has been validated in a variety of healthcare domains including health education, physicians' preventive practice and individual health prevention behaviors ${ }^{[9-11]}$. Characteristics of the health care organization in terms of learning environment are reported to have an impact on the beliefs of an individual towards EBP as well ${ }^{[12]}$. The aim of our current study is to better understand the relationship between self-efficacy and EBP, specifically focusing upon clinical environments that have previously undergone efforts to create an environment that supports EBP. Results provide guidance regarding sustained integration of EBP in the daily routines of clinicians.

We suggest that EBP is a set of behaviors that result from individuals generating new knowledge and justifying (verifying the correctness or reasonableness of that knowledge) by sharing it with others in the organization. To enact EBP an individual must first make an effort to acquire evidence that is new to him or her. Individuals then apply that evidence to their practice and in doing so generate new knowledge in their organization. We propose that to acquire and apply the evidence the individual must believe that they are capable, that is, exhibit self-efficacy in term of EBP-related behaviors. Finally, when new knowledge is acquired and applied, it is shared with others in the organization. Through sharing the individual seeks to justify the new knowledge, that is, verify with others that the knowledge is valid and applicable in the organization's practice. This sharing and justifying facilitates the EBP to extend beyond the realm of the individual and into the daily practice of clinicians.

\section{Conceptual framework}

Self-efficacy is a core construct in Bandura's social cognitive theory and is defined as the belief "in one's capabilities to organize and execute the courses of action required to produce given attainments" ${ }^{[13]}$. Bandura posits that information and skills are not sufficient to affect behavior. Individuals will only take action if they believe that they can produce desired effects through those actions. People avoid situations they think they will be unable to handle, but will take on even intimidating tasks when they believe they can handle them successfully ${ }^{[14]}$. We suggest that an individual's belief about their self-efficacy related to EBP influences the level to which he or she generates and justifies new knowledge about EBP.

Knowledge is defined as a justified belief that increases an individual's capacity for effective action ${ }^{[15,16]}$. The belief must also be linked in some way to effective action, so that the creation of knowledge also implies the creation of something of value $^{[17]}$. Potential new knowledge must be justified and deemed meaningful in the current context. It is often justified by getting feedback from others ${ }^{[18]}$ and interacting with others ${ }^{[19]}$. Feedback allows individuals to compare their tentative knowledge to others' tentative or existing knowledge, and to validate the viability and value of the tentative knowledge ${ }^{[20]}$.

One of the core activities of EBP is finding evidence related to an individual's practice. Evidence cannot be put into practice until an individual knows about it. After evidence is acquired it can be applied. Activities associated with applying evidence include collecting data about patient problems, changing practice based on evidence, generating PICO questions and evaluating the effect of practice change ${ }^{[21]}$. When an individual acquires evidence and applies it to her practice, she is generating new knowledge. After the new knowledge is generated, it is justified by sharing the evidence with colleagues, 
patients and family members. The process of sharing helps the individual confirm that the new knowledge is valid and valued by others, and also helps to spread EBP within the organization.

We examine the relationships between self-efficacy and three activities associated with EBP new knowledge generation and justification: acquisition of evidence, applying evidence and sharing evidence. We hypothesize that a perception of self-efficacy will increase the generation and justification of EBP-related knowledge, which includes the acquisition, application and sharing of evidence. The acquisition of evidence will act to increase the application of evidence as well as the sharing of evidence. Finally, the application of evidence will increase the sharing of evidence with others in the organization. Figure 1 displays the hypothesized model as specified.

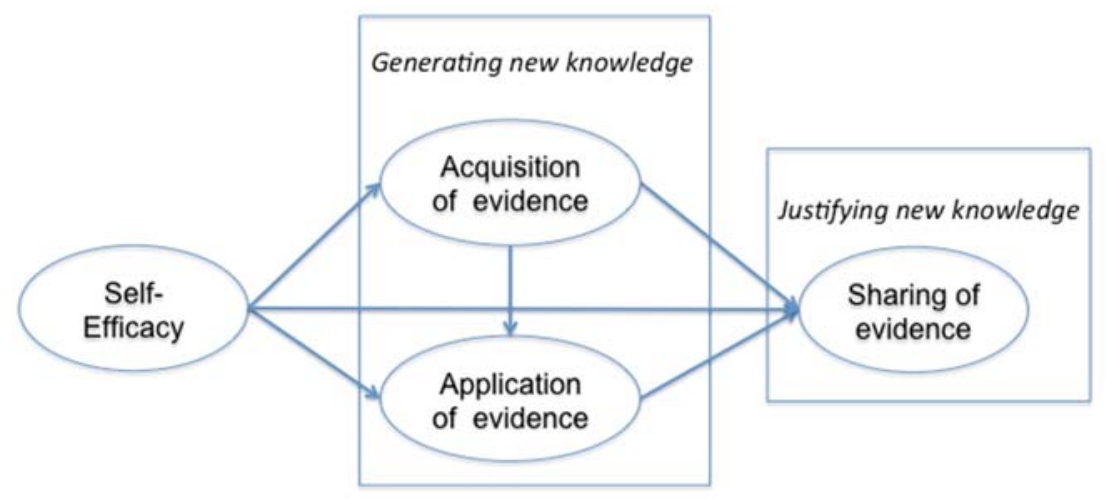

Figure 1. Hypothesized Model

\section{Methods}

\subsection{Data and subjects}

To research these relationships we surveyed nurses as well as other clinicians and hospital quality leaders in organizations that were actively engaged in implementing EBP. Study respondents were sampled from acute care hospitals participating in the Clinical Practice Model Resource Center (CPMRC), a collaborative consortium of health care organizations working to guide the implementation of EBP into the work worlds of clinicians ${ }^{[22]}$. Survey questions came from the Evidence-Based Practice Beliefs and Implementation Scales, as developed by Melnyk, Fineout-Overholt and Mays ${ }^{\text {[21] }}$.

Surveys were administered in person to participating clinicians at the annual CPMRC conference, as well as distributed online via the clinical quality manager at 300 CPMRC partner sites located throughout the United States. Of the approximately 50 surveys that were distributed in person at the CPMRC conference 22 completed surveys were returned, a response rate of $44 \%$. Two-hundred and fourteen completed online surveys were obtained, resulting in a total sample of 236 clinicians.

\subsection{Analysis}

Exploration of the data was completed through structural equation modeling via the AMOS software package ${ }^{[23]}$. An advantage of structural equation modeling is the ability to model measurement without an assumption of perfect measurement as required when using ordinary least squares (OLS) regression. For this study latent variables were constructed to represent the domains of application of EBP principles in practice, generation of new knowledge, behaviors to justify new knowledge, and self-efficacy. Prior to development of the latent variables an exploratory factor analysis was completed to indicate which of the survey items loaded significantly on the proposed constructs. A reliability coefficient (Cronbach's alpha) was then obtained for each of the constructed variables representing the domains of interest. Selected 
survey items, factor loadings and reliability coefficients for the four latent variables (application of EBP principles in practice, generation of new knowledge, behaviors to justify new knowledge, and self-efficacy) are noted in Table 1.

Table 1. Factor Loadings and Reliability Coefficients for Latent Variables

\begin{tabular}{|c|c|c|c|}
\hline Latent variable & Survey items & Factor loading & Cronbach's alpha \\
\hline \multirow[t]{6}{*}{ Self-Efficacy } & & & .861 \\
\hline & $\begin{array}{l}\text { I am confident about my ability to implement EBP } \\
\text { where I work }\end{array}$ & .878 & \\
\hline & $\begin{array}{l}\text { I know how to implement EBP sufficiently enough to } \\
\text { make practice changes }\end{array}$ & .835 & \\
\hline & $\begin{array}{l}\text { I am sure about how to measure the outcomes of } \\
\text { clinical care }\end{array}$ & .816 & \\
\hline & I believe I can overcome barriers to EBP & .739 & \\
\hline & $\begin{array}{l}\text { I believe that I can search for the best evidence to } \\
\text { answer my clinical questions in a time efficient way }\end{array}$ & .701 & \\
\hline \multirow[t]{4}{*}{ Acquisition of evidence } & & & .837 \\
\hline & $\begin{array}{l}\text { Accessed the Cochrane database to do systematic } \\
\text { reviews }\end{array}$ & .896 & \\
\hline & Accessed the National Guidelines Clearinghouse & .891 & \\
\hline & Read and critically appraised a research study & .827 & \\
\hline \multirow[t]{5}{*}{ Application of evidence } & & & .801 \\
\hline & Evaluated the outcomes of a practice change & .843 & \\
\hline & Collected data on a patient problem & .799 & \\
\hline & Used evidence to change my clinical practice & .793 & \\
\hline & Generated a PICO question about my clinical practice & .759 & \\
\hline \multirow[t]{4}{*}{ Sharing of evidence } & & & .807 \\
\hline & $\begin{array}{l}\text { Shared evidence from a study or studies in the form of } \\
\text { a report or presentation to }>2 \text { colleagues }\end{array}$ & .876 & \\
\hline & $\begin{array}{l}\text { Informally discussed evidence from a research study } \\
\text { with a colleague }\end{array}$ & .863 & \\
\hline & $\begin{array}{l}\text { Shared evidence from a research study with a } \\
\text { patient/family member }\end{array}$ & .808 & \\
\hline
\end{tabular}

A confirmatory factor analysis, or measurement model, was constructed based upon the results of the exploratory factor analysis. The measurement model confirmed significant factor loadings on the latent variables for each of the selected survey items and demonstrated adequate model fit to move forward with the analysis. Model fit statistics for the measurement model were: chi-squared $=185.271$, degrees of freedom $(\mathrm{d} f)=.84$, chi-squared $/ \mathrm{d} f=2.206$, comparative fit index $(\mathrm{CFI})=.946$, and Root Mean Square Error of Approximation= .072. A structural model was then developed to test the proposed relationships.

\section{Results}

Our analysis examined the relationships between the application of EBP, generation of new knowledge regarding EBP, behaviors to justify that knowledge, and self-efficacy. Our sample was purposefully chosen to represent a wide range of clinical backgrounds and health care professionals who were invested in quality within their respective hospital settings. Interestingly, responses to selected survey items reflected variability between the different EBP activities. For example, while $87 \%$ of clinicians noted they had used evidence to change clinical practice at least once during the 8 weeks prior to survey administration, and $89 \%$ had discussed evidence from a research study with a colleague, only $54 \%$ had shared 
evidence with a patient or family member and $68 \%$ of respondents had not accessed the National Guidelines Clearinghouse in the previous 8 weeks. Frequency of responses to selected survey items from the implementation and beliefs scales are found in Tables 2 and 3.

Table 2. Selected survey items frequencies: Question 1*

\begin{tabular}{|c|c|c|c|c|c|c|c|}
\hline Survey item & 0 times & $1-3$ & 4-5 & 6-7 & $>8$ & Missing & Total \\
\hline Used evidence to change my clinical practice & $12 \%$ & $39 \%$ & $22 \%$ & $8 \%$ & $18 \%$ & $1 \%$ & $100 \%$ \\
\hline Generated a PICO question about my clinical practice & $64 \%$ & $19 \%$ & $8 \%$ & $3 \%$ & $1 \%$ & $5 \%$ & $100 \%$ \\
\hline Collected data on a patient problem & $28 \%$ & $28 \%$ & $14 \%$ & $10 \%$ & $18 \%$ & $2 \%$ & $100 \%$ \\
\hline Evaluated the outcomes of a practice change & $28 \%$ & $42 \%$ & $14 \%$ & $5 \%$ & $9 \%$ & $2 \%$ & $100 \%$ \\
\hline Read and critically appraised a clinical research study & $32 \%$ & $36 \%$ & $11 \%$ & $8 \%$ & $10 \%$ & $3 \%$ & $100 \%$ \\
\hline Accessed the Cochrane database of systematic reviews & $63 \%$ & $19 \%$ & $5 \%$ & $2 \%$ & $7 \%$ & $4 \%$ & $100 \%$ \\
\hline Accessed the National Guidelines Clearinghouse & $68 \%$ & $16 \%$ & $3 \%$ & $4 \%$ & $6 \%$ & $3 \%$ & $100 \%$ \\
\hline $\begin{array}{l}\text { Informally discussed evidence from a research study } \\
\text { with a colleague }\end{array}$ & $10 \%$ & $37 \%$ & $25 \%$ & $10 \%$ & $18 \%$ & $1 \%$ & $100 \%$ \\
\hline $\begin{array}{l}\text { Shared evidence from a study or studies in the form of a } \\
\text { report or presentation to }>2 \text { colleagues }\end{array}$ & $39 \%$ & $34 \%$ & $13 \%$ & $2 \%$ & $10 \%$ & $2 \%$ & $100 \%$ \\
\hline Shared evidence with a patient or family member & $43 \%$ & $35 \%$ & $9 \%$ & $5 \%$ & $5 \%$ & $3 \%$ & $100 \%$ \\
\hline
\end{tabular}

*Question asked: How often has each item applied to you in the past 8 weeks?

Table 3. Selected survey items frequencies: Question 2*

\begin{tabular}{|c|c|c|c|c|c|c|c|}
\hline Survey item & $\begin{array}{l}\text { Strongly } \\
\text { disagree }\end{array}$ & Disagree & Neither & Agree & $\begin{array}{l}\text { Strongly } \\
\text { Agree }\end{array}$ & Missing & Total \\
\hline $\begin{array}{l}\text { I believe that I can search for the best } \\
\text { evidence to answer clinical questions in a } \\
\text { time efficient way }\end{array}$ & $3 \%$ & $17 \%$ & $19 \%$ & $46 \%$ & $12 \%$ & $3 \%$ & $100 \%$ \\
\hline $\begin{array}{l}\text { I believe I can overcome barriers to imple- } \\
\text { menting EBP }\end{array}$ & $1 \%$ & $7 \%$ & $31 \%$ & $52 \%$ & $5 \%$ & $4 \%$ & $100 \%$ \\
\hline $\begin{array}{l}\text { I am sure about how to measure the out- } \\
\text { comes of clinical care }\end{array}$ & $2 \%$ & $18 \%$ & $25 \%$ & $39 \%$ & $11 \%$ & $5 \%$ & $100 \%$ \\
\hline $\begin{array}{l}\text { I know how to implement EBP suffi- } \\
\text { ciently enough to make practice changes }\end{array}$ & $2 \%$ & $18 \%$ & $23 \%$ & $45 \%$ & $7 \%$ & $5 \%$ & $100 \%$ \\
\hline $\begin{array}{l}\text { I believe that I can search for the best evid- } \\
\text { ence to answer clinical questions in a time } \\
\text { efficient way }\end{array}$ & $3 \%$ & $17 \%$ & $19 \%$ & $46 \%$ & $12 \%$ & $3 \%$ & $100 \%$ \\
\hline
\end{tabular}

*Question asked: How strongly to you agree or disagree with this statement?

Table 4. Standardized Parameter Estimates for Structural Model

\begin{tabular}{llll}
\hline Parameter & Acquisition of evidence & Application of evidence & Sharing of evidence \\
\hline Self-Efficacy & $.485^{* * *}$ & $.275^{* * *}$ & -.006 \\
Acquisition of evidence & & $.698^{* * *}$ & $.564^{* * *}$ \\
Application of evidence & & $.461^{* * *}$ \\
\hline
\end{tabular}

$* * * P<0.001$

Results of the structural equation model indicated that self-efficacy increased the acquisition of evidence and application of evidence. Unexpectedly, controlling for the effect of other variables, self-efficacy did not exert a significant influence on sharing evidence. Acquisition of evidence increased both application of evidence and sharing of evidence. Application of evidence then increased sharing of evidence. Fit statistics indicated an adequate fit for the hypothesized model as specified. Fit statistics were: chi-squared $=196.042$, degrees of freedom $d f=99$, chi-squared $/ d f=1.98$, Comparative Fit 
Index $(\mathrm{CFI})=.950$, and Root Mean Square Approximation of Error $(\mathrm{RMSEA})=.065$. Standardized parameter estimates from the structural model can be found in Table 4 and Figure 2.

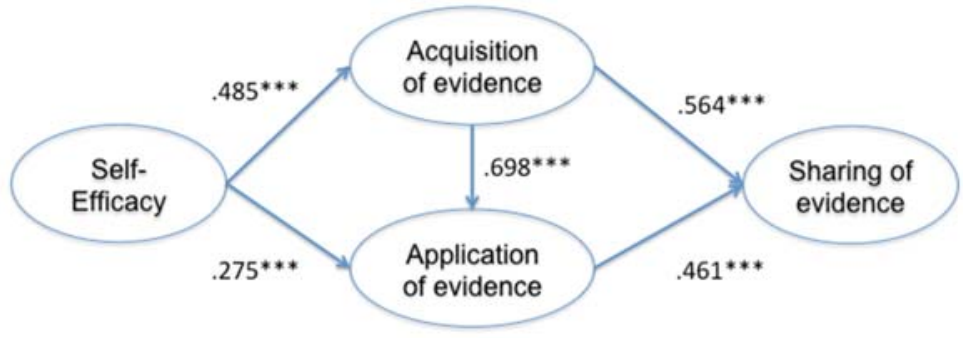

Figure 2. Final Structural Equation Model Results

*** Significant at $\mathrm{p}<0.001$ level. Note: only significant paths are shown

\section{Discussion}

Our analysis tested the idea that a perception of self-efficacy, as defined by social cognitive theory, would positively influence the behavioral components necessary (generation of new knowledge and justifying of that knowledge) to maintain EBP implementation efforts within an organization. Results indicated that self-efficacy positively influenced evidence acquisition and application. Finding evidence-based practices that relate to a clinical context or a specific patient case can be challenging and can take substantial time in a nurse's busy schedule. Even if evidence-based guidelines are readily available, they often require tailoring to the immediate task at hand, which takes further time, energy and effort. Clinicians are more likely to expend this effort if they believe they have the capabilities and skills to succeed in finding and applying evidence-based practices. Continuing education, quality improvement teams and EBP mentors are just a few of the ways that can help boost clinicians' feelings of self-efficacy in terms of EBP.

Self-efficacy however had no significant influence on sharing evidence. Further investigation is needed to examine the motivation for sharing, and how this motivation may be influenced by self-efficacy. It is possible that clinicians who felt confident and well supported in their ability to apply evidence were less motivated to justify their EBP knowledge, and thus did not feel the need to share the knowledge with others. Interestingly, sharing behaviors were positively influenced by application of evidence. Our model suggests that while the direct relationship between self-efficacy and sharing evidence was non-significant, self-efficacy influenced the sharing of evidence indirectly through increasing the likelihood that evidence will be acquired and applied by the clinician.

Additionally, the strongest path coefficient in the model was between the acquisition of evidence and the application of evidence. Together with the strong positive effect of self-efficacy on acquisition of evidence, these results highlight the importance of providing clinicians with the education, technology, and support to assure their ability to acquire new evidence, so that it can be applied and shared with others. Our results indicate that when clinicians have the tools and skills to acquire information regarding EBP they are more likely to apply EBP in patient care. Thus, nurse educators have potential to play a significant role in the continued application of evidence in clinical practice.

Our study was unique in that it selectively sampled a wide variety of clinicians with quality improvement experience working within organizations that are actively implementing EBP. This strategy allowed us to go in-depth into EBP utilization post-initial implementation efforts. Our sampling technique resulted in a number of limitations as well. First, because of concerns regarding workplace confidentiality we were unable to complete analyses based upon job title or clinical role. Future research should investigate the possibility that influence of self- efficacy differs between clinical disciplines. Second, our sample was selected based upon the recommendation of a clinical quality manager and may not be 
representative of hospital-based clinicians as a whole. The purpose of our analysis was to examine the influence of self-efficacy within this specially selected group, but further research would benefit from a more representative sample.

Despite these limitations our model demonstrated that efforts to promote self-efficacy in clinicians are powerful in that they directly promote the acquisition and application of evidence, and indirectly encourage communication between clinicians in an effort of justify and reinforce new knowledge. The model validates prior frameworks that have suggested that self-efficacy is positively related to EBP and contributes to the literature by suggesting that self-efficacy enhances EBP by positively influencing a clinician's effort to generate new knowledge. The strength of the relationship between evidence acquisition and evidence application suggests that efforts to boost self-efficacy should focus on helping clinicians become more comfortable with actions related to acquiring evidence and generating new knowledge.

\section{Conclusion}

Efforts to promote self-efficacy in clinicians are powerful in that they directly promote the acquisition and application of evidence, and indirectly encourage communication between clinicians in an effort to justify and reinforce new knowledge. The strength of the relationship between evidence acquisition and evidence application suggests that efforts to boost self-efficacy should focus on helping clinicians become more comfortable with actions related to acquiring evidence and generating new knowledge.

\section{Acknowledgements}

We would like to acknowledge the assistance of the CPM Resource Center, specifically Cathy Schwartz and Kathy Wyngarden, in the administration of the clinician survey.

\section{References}

[1] Ring N, Malcolm C, Coull A, Murphy-Black T, Watterson A. Nursing best practice statements: An exploration of their implementation in clinical practice. Journal of Clinical Nursing. 2005; 14: 1048-1058. PMid:16164522 http://dx.doi.org/10.1111/j.1365-2702.2005.01225.x

[2] Pogorzelska M, Larson EL. Assessment of attitudes of intensive care unit staff toward clinical practice guidelines. DCCN. 2008; 27: 30-38. PMid:18091633 http://dx.doi.org/10.1097/01.DCC.0000304673.29616.23

[3] Worrall G, Chaulk P, Freake D. The effects of clinical practice guidelines on patient outcomes in primary care: A systematic review. CMAJ. 1997; 156: 1705-1712. PMid:9220922

[4] Shiffman RN, Dixon J, Brandt C, Essaihi A, Hsiao A, Michel G, et. al. The guideline implementability appraisal (GLIA): development of an instrument to identify obstacles to guideline implementation. BMC Medical Informatics and Decision Making. 2005; 5: 23. PMid:16048653 http://dx.doi.org/10.1186/1472-6947-5-23

[5] Hader JM, White R, Lewis S, Foreman JL, McDonald PW, Thompson LG. Doctors' views of clinical practice guidelines: A qualitative exploration using innovation theory. J Eval Clin Pract. 2007; 13: 601-606. PMid:17683302 http://dx.doi.org/10.1111/j.1365-2753.2007.00856.x

[6] Koh SS, Manias E, Hutchinson AM, Donath S, Johnston L. Nurses perceived barriers to the implementation of a fall prevention clinical practice guideline in Singapore hospitals. BMC Health Serv Res. 2008; 8: 105. PMid:18485235 http://dx.doi.org/10.1186/1472-6963-8-105

[7] Damschroder LJ, Aron D, Keith RE, Kirsch SR, Alexander JA, Lowery JC. Fostering implementation of health services researching findings into practice: A consolidated framework for advancing implementation science. IS. 2009 ; 4: 1.

[8] Melnyk B, Fineout-Overholt E, Giggleman M, Cruz R. Correlates among cognitive beliefs, EBP implementation, organizational culture, cohesion and job satisfaction in evidence-based practice mentors from a community hospital system. Nursing Outlook. 2010; 58: 301-308. PMid:21074647 http://dx.doi.org/10.1016/j.outlook.2010.06.002

[9] Kok G, de Vries H, Mudde AN, Strecher, VJ. Planned health education and the role of self-efficacy: Dutch research. Health Education Research. 1991; 6: 231-238. http://dx.doi.org/10.1093/her/6.2.231

[10] Manika D, Golden LL. Self-efficacy, threat, knowledge and information receptivity: Exploring pandemic prevention behaviors to enhance societal welfare. Academy of Health Care Management Journal. 2011; 7: 31-44. 
[11] Mann KV, Putnam RW. Physicians' perceptions of their role in cardiovascular risk reduction. Prev Med. 1989; 19 : 45-58. http://dx.doi.org/10.1016/0091-7435(89)90053-4

[12] Estrada N. Exploring perceptions of a learning organization by RNs and relationship to EBP beliefs and implementation in the acute care setting. Worldviews on Evidence-Based Nursing. 2009; 6: 200-209. PMid:19686224 http://dx.doi.org/10.1111/j.1741-6787.2009.00161.x

[13] Bandura A. Self-efficacy: the exercise of control. New York: W. H. Freeman, 1997.

[14] Bandura A. Social learning theory. Englewood Cliffs, NJ: Prentice-Hall, 1977.

[15] Alavi M, Leidner D. Knowledge management and knowledge management systems: Conceptual foundations and research issues. MIS Quarterly. 2001; 25: 107-136. http://dx.doi.org/10.2307/3250961

[16] Nonaka I. A dynamic theory of organizational knowledge creation. Organization Science. 1994; 5: 14-37. http://dx.doi.org/10.1287/orsc.5.1.14

[17] von Krogh G. Care in knowledge creation. California Management Review. 1998; 40: 133-153. http://dx.doi.org/10.2307/41165947

[18] Cross R, Sproull L. More than an answer: Information relationships for actionable knowledge. Organization Science. 2004; 15: 446-462. http://dx.doi.org/10.1287/orsc.1040.0075

[19] Nonaka I, von Krogh G. Tacit knowledge and knowledge conversion: Controversy and advancement in organizational knowledge creation theory. Organization Science. 2009; 20: 635-652. http://dx.doi.org/10.1287/orsc.1080.0412

[20] Wasko M, Faraj S. Why should I share? Examining social capital and knowledge contribution in electronic networks of practice. MIS Quarterly. 2005; 29: 35-57.

[21] Melnyk B, Fineout-Overholt E, Mays M. The evidence-based practice beliefs and implementation scales: Psychometric properties of two new instruments. Worldviews on Evidence Based Nursing. 2008; 5: 208-216. PMid:19076922 http://dx.doi.org/10.1111/j.1741-6787.2008.00126.x

[22] Abrahamson K, Arling PA, Wesorick B, Anderson JG. An application of the socio-technical systems approach to implementation of electronic evidence into practice: The clinical practice model framework. International Journal of Quality and Reliable E-Health. 2012; 1: 7-30.

[23] Arbuckle JL. Amos 6.0 User’s guide. Chicago, IL: SPSS, 2005. 